\title{
В.Н. Некрасов
}

\section{ТЕХНОЛОГИИ В УГОЛОВНОМ ЗАКОНОДАТЕЛЬСТВЕ РОССИИ: ПРОБЛЕМЫ И ПЕРСПЕКТИВЫ}

\begin{abstract}
Предпринята попытка рассмотреть вопросы влияния такого вида результатов инновационной деятельности, как технологии, на отечественный уголовный закон и сделать вывод о готовности ныне действующего закона к появляющчимся новществам. Изучены технологические инновачии как орудия и средства преступления. Исследованы проблемные вопросы конструирования Уголовного кодекса РФ с использованием новых понятий, связанных с развитием инновационной деятельности.

Ключевые слова: уголовный закон, инновационная деятельность, преступление.
\end{abstract}

В результате развития инновационных технологий, при всех их несомненных благах в сферах экономики, образования и культуры, все острее становится проблема противодействия преступности в данной сфере. Сегодня никого не удивишь преступлениями, совершенными с использованием электронных средств платежа, компьютерных программ и т.п. Более того, стремительное развитие робототехники и искусственного интеллекта приводит к тому, что в мире уже появляются идеи признания роботов в качестве самостоятельных субъектов права, в том числе уголовного [1]. Вместе с тем в целом для законодателя проблема включения технологий в уголовное законодательство, в одной стороны, не нова, с другой же обладает рядом специфических особенностей в связи с развитием инновационных технологий последнего времени. В данной работе автор попытался рассмотреть вопросы влияния такого вида результатов инновационной деятельности, как технологии, на отечественный уголовный закон и разобраться, готов ли законодатель к их появлению.

Начать следует с того, что в ныне действующем Уголовном кодексе РФ (далее - УК) законодатель ни разу не использует применительно к техническим нововведениям единого обобщающего понятия, которое позволило бы в совокупности охарактеризовать различные их элементы. Вместе с тем традиционно законодатель оперирует такими частными терминами, как «орудия», «средства», «оборудование», «система» и т.п. Стоит отметить и то, что в действующем УК не упоминаются понятия «робот» или «роботизированная система» и тем более «искусственный интеллект». В этой связи автор для характеристики современных технических новшеств будет использовать обобщающие традиционные как для юриспруденции, так и для других отраслей, например философии, понятия «техника» и «технология», которые, в свою очередь, применительно к данному исследованию 
являются особым видом результатов инновационной деятельности. Под упомянутыми терминами понимается совокупность введенных в употребление новых или значительно улучшенных технических орудий, устройств и сооружений. В этом случае техника представляет собой артефакты, т.е. систему искусственно созданных человеком средств для преобразования природы [2. С. 10].

При рассмотрении обозначенного вопроса в первую очередь на ум приходит мысль о том, что технические нововведения в УК рассматриваются как орудия или средства совершения преступления. Так, средством, используемым для совершения преступления, предусмотренного ст. 159.3 УК, являются электронные средства платежа, под которыми, исходя из ст. 3 Федерального закона от 27 июня 2011 г. № 161-Ф3 «О национальной платежной системе», следует понимать средство и (или) способ, позволяющие клиенту оператора по переводу денежных средств составлять, удостоверять и передавать распоряжения в целях осуществления перевода денежных средств в рамках применяемых форм безналичных расчетов с использованием информационно-коммуникационных технологий, электронных носителей информации, в том числе платежных карт, а также иных технических устройств [3]. Иными словами, особенность анализируемого состава преступления заключается в том, что преступление совершается благодаря такой технологии, как электронные средства платежа.

В теории уголовного права существует множество точек зрения относительно вопроса о разграничении понятий «орудие» и «средство» преступления [4. С. 58-63]. В рамках данного исследования хочется обратить внимание на ряд вопросов. В частности, в УК РФ анализируемые понятия понимаются неоднозначно, что не способствует стабильности правоприменительной практики. Так, в ч. 1 ст. 30 УК законодатель для характеристики приготовления к преступлению использует словосочетание «приспособление лицом средств или орудий совершения преступления», что позволяет судить о равнозначном и самостоятельном статусе указанных понятий. В свою очередь, уже в п. «Г» ч. 1 ст. 104.1 УК законодатель использует следующую формулировку: «...орудий, оборудования или иных средств совершения преступления, принадлежащих обвиняемому». Анализ указанной нормы свидетельствует о том, что, во-первых, законодатель наравне с орудиями и средствами преступления рассматривает оборудование как самостоятельное понятие, во-вторых, орудия и оборудование являются средствами совершения преступления. Иными словами, в двух приведенных нормах наблюдается противоречивая ситуация: в одном случае орудия и средства рассматриваются как самостоятельные и равнозначные понятия, а в другом - орудия являются составным элементом более общего понятия «средства совершения преступления». Кроме того, законодатель дополнительно к указанным понятиям вводит еще и понятие «оборудование», которое в тексте УК понимается не только как средство или орудие, но и как, например, материалы. Приведенный пример, с одной стороны, позволяет сделать вывод о том, что законодатель в УК использует понятия, которые 
не отличаются единообразием и точностью. С другой же стороны, технические новшества, например оборудование, отечественным законодателем всетаки рассматриваются как орудия и средства совершения преступления.

В дополнение к сказанному следует отметить, что на этом проблемы не заканчиваются. Перечисленные понятия традиционно использовались законодателем для конструирования норм уголовного закона РФ. Вместе с тем сегодня в связи с активным развитием инновационной деятельности появляются все новые технические решения, которых, во-первых, не было раньше, и, во-вторых, они стали обладать рядом специфических особенностей.

В разные исторические периоды содержание термина «техника» раскрывалось по-разному. В частности, на этапе использования ручных орудий труда, когда важным было умение человека работать ими, под техникой понимались искусство и мастерство. Сегодня, когда техника внедрилась во все сферы человеческой деятельности, под ней понимают искусственно созданные средства человеческой деятельности и, более того, овеществленное знание [2. С. 10].

Новые виды техники в последние годы нередко называют высокими технологиями, которые стали обладать рядом специфических характеристик, в отличие от технологий предыдущих периодов. Как верно отмечает Е.А. Жукова, принципиальными отличиями высоких технологий от других технологий являются в том числе стремление исключить непосредственное участие человека из сферы постановки задач, перестраивание форм культуры и формирование различных моделей поведения человека [5. С. 9].

Иными словами, под воздействием инновационной деятельности и такой ее составляющей, как развитие технологий, происходит трансформация общественных отношений. А раз общественные отношения претерпевают определенные изменения, следовательно, происходят модификации и в объекте преступления, под которым традиционно понимаются общественные отношения в определенных сферах.

Сегодня все больше ученых-философов отмечают тенденцию изменения последовательности отношений «человек-техника» в результате развития инновационной деятельности. Так, члены Римского клуба видят угрозу действительности не в развитии техники как таковой, а в изменениях личности, системы ценностей, которые происходят под влиянием техники [6. С. 171]. По мнению А.А. Дурова, В.А. Починской и А.Р. Шариповой, «расстояние между человеком и техникой стремительно сокращается. По мере его сокращения отчетливо обозначаются две тенденции - технизация человека и гуманизация машины. Если эти тенденции “разойдутся" друг с другом, то картины из фантастических романов перестанут быть фантастическими: роботу, более человечному, чем человек, и человекупрограмме будет тесно на страницах sci-fi» [7. C. 9]. Далее указанные авторы пытаются ответить на вопрос: «Можно ли отказать технике в субъектности, если она теснит и окружает человека, переходит границы и вызывает зависимость?» На этот отвлеченный вопрос можно ответить и положительно, и отрицательно... Отрицательный ответ связан с возможно- 
стью бунта творения против творца. По выражению М.Н. Эпштейна, если человек создан по образу и подобию Бога и наделен свободой воли, то он может передавать эту «эстафету» своим творениям [7. С. 9].

Конечно, до признания техники, в частности роботов, оснащенных системами искусственного интеллекта высокого уровня, субъектами уголовного права еще далеко, однако этот вопрос все острее встает перед законодателем, и решать его придется. В этой связи автор придерживается позиции, согласно которой в преступлениях, связанных с результатами инновационной деятельности, подлежит установлению вина человека. Здесь нельзя не согласиться с В. Цветовым, который отмечал, что «чем выше и ярче высоты научно-технического прогресса, тем важнее становится человек, без которого роботы, ЭВМ, станки с числовым программным управлением не более чем замысловатая груда металла»[8. С. 37].

Вместе с тем в отечественном уголовном законе сегодня уже имеют место ранее не встречавшиеся дефиниции, позволяющие судить о новых возможностях техники, которые только стимулируют дискуссию о правом положении технологий как в уголовном праве, так и в законодательстве в целом. В частности, при конструировании ст. 274.1 УК законодатель использовал при характеристике нарушения правил эксплуатации средств хранения, обработки или передачи охраняемой компьютерной информации словосочетание «автоматизированные системы управления». Традиционно под последними понимается комплекс аппаратных и программных средств, а также персонала, предназначенный для управления различными процессами в рамках технологического процесса, производства, предприятия. Автоматизированные системы управления применяются в различных отраслях промышленности, энергетике, транспорте и т.п. [9]. Примечательно, что в Толковом словаре русского языка С.И. Ожегова слово «автоматизм» определено следующим образом: «Механичность, непроизвольность действий, движений» [10]. В свою очередь, в том же словаре слово «система» понимается как «определенный порядок в расположении и связи действий», а слово «управление» - как «совокупность приборов, приспособлений, устройств, посредством которых управляется ход машины, механизма» [Там же]. Исходя из формального толкования перечисленных слов, получается, что автоматизированная система управления представляет собой механический, в ряде случаев непроизвольный порядок расположения действий по управлению техническими приборами. В этой связи обращают на себя внимание два момента. Во-первых, толкование слова «автоматизированный» предполагает в том числе непроизвольность, иными словами, неконтролируемость действий. Для сферы права, особенно уголовного, это крайне опасная конструкция. В этой связи включение анализируемого понятия в текст уголовного закона представляется преждевременным.

Во-вторых, автоматизированная система управления, как мы отмечали ранее, предполагает управление техническими средства, а не человеком. Сегодня же происходит совсем по-другому. Конечно, в первую очередь автоматизированные системы управления предназначены для управления 
процессами, но не только. В последние годы все чаще рассматриваемые системы используются для управления человеком. Как отмечается в одной из статей, посвященных использованию информационных технологий в системе управления персоналом, «на сегодняшний день использование информационных технологий в управлении персоналом - это необходимое условие для того, чтобы обеспечить эффективную работу любой компании» [11. С. 28-31].

Получается, что человек добровольно передает часть своих функций управления другими людьми автоматизированным системам. Следовательно, логичным является вопрос: «Кто в такой ситуации должен нести ответственность за допущенные нарушения в результате сбоя автоматизированной системы управления?» Из имеющегося опыта взаимодействия человека и техники следует, что ответственность несет человек. Вместе с тем в результате развития инновационной деятельности, как мы отмечали ранее, системы взаимоотношений человека и техники меняются, в результате чего так однозначно ответить на обозначенный вопрос в будущем будет все сложнее. Поэтому законодателю следует более внимательно относиться к использованию такого средства законодательной техники, как терминология уголовного закона, и более обдуманно включать в его текст новые дефиниции.

Другой аспект рассматриваемой проблемы заключается в том, что общественные отношения под воздействием инновационной деятельности претерпевают определенные изменения. Следовательно, трансформируется и объект преступления. Например, такой традиционный объект преступления, как собственность, известный законодателю с первых законодательных источников уловного права, наделяется новыми, доселе неизвестными свойствами. С формированием общества, в котором основными производственными ресурсами выступают информация и знания, а средства их создания и передачи становятся доступными множеству отдельных людей, возникает ситуация, когда, с одной стороны, каждый желающий может приобрести современные информационные средствами в личное владение, а с другой - люди, которые не могут эффективно присваивать сложные информационные продукты, не могут ими обладать в полной мере [2. С. 5558]. В результате появляется новый вид собственности, а именно интеллектуальная собственность, которая также подлежит уголовно-правовой охране.

Вместе с тем, по нашему мнению, оперирование учеными и практиками таким понятием, как «интеллектуальная собственность», вызывает противоречия. Так, по своей сути интеллектуальную собственность к собственности отнести нельзя, это частично подтверждает и законодатель, располагая значительное число норм, посягающих на рассматриваемую группу отношений, за пределами главы «Преступления против собственности». Кроме того, как верно отмечает Н.А. Лопашенко, «...к имуществу не относятся и, значит, предметом посягательств на собственность не являются интеллектуальная собственность и нематериальные блага. Последние не 
несут в себе экономического содержания собственности, а следовательно, лишены и ее юридического содержания» [12. С. 34-35]. Отмеченное также является проблемой, которую придется впоследствии решать.

В данной работе автор попытался обозначить наиболее актуальные вопросы, которые встают перед законодателем в связи с развитием технологий и инновационной деятельности. Представляется, что сегодня назрела необходимость объединения норм в области преступлений, посягающих на инновационную деятельность, в отдельную группу норм. Указанные общественные отношения обладают рядом особенностей, позволяющих рассмотреть вопрос о формировании их в отдельный видовой объект преступления, на часть из которых автор указал в данной работе. Выделение групп преступлений в области инновационной деятельности будет иметь серьезное значение. В частности, это позволит устанавливать общественную опасность применительно к группе преступлений, а также анализировать изменения степени общественной опасности преступления в зависимости от видов квалифицирующих и привилигирующих обстоятельств. Кроме того, проведенное деление будет способствовать повышению эффективности дифференциации ответственности, системности уголовного закона, а также позволит облегчить процесс квалификации уголовно наказуемого деяния.

\section{Лuтература}

1. Мухамедзянова Д. Роботы должны нести уголовную ответственность. URL: https://hightech.fm/2017/04/04/intelligence-systems (дата обращения: 05.11.2018).

2. Поломошнов А.Ф., Лаврухина И.М., Поломошнов П.А. Философия и современный мир : курс лекций. Персиановский : Донской ГАУ, 2015. 224 с.

3. О национальной платежной системе : федеральный закон от 27.06.2011 № 161-Ф3 // СПС КонсультантПлюс.

4. Денисова А.С. Уголовно-правовое значение орудий и средств совершения преступления : дис. ... канд. юрид. наук. М., 2005. 202 с.

5. Жукова Е.А. Нi-Теch: динамика взаимодействий науки, общества и технологий : автореф. дис. ... д-ра филос. наук. Томск, 2007. 357 с.

6. Власова Е.М. Изменение отношения человек - техника в современном обществе: проблема нового гуманизма // Международный журнал прикладных и фундаментальных исследований. 2015. № 1. С. 170-173.

7. Дуров А.А., Починская В.А., Шарипова А.Р. Механизация человека и гуманизация машины: тенденции существования человека и техники // Социум и власть. 2018. № 3 (71). C. 7-14.

8. Барбакова К.Г., Войтенко Л.И., Гудков Л.Д. и др. ФРГ глазами западногерманских социологов : техника - интеллектуалы - культура / отв. ред. Ю.Н. Давыдов. М. : Наука, 1989. 344 с.

9. Автоматизированная система управления. URL: https://ru.wikipedia.org/wiki/Авто матизированная_система_управления (дата обращения: 22.12.2018).

10. Ожегов С.И. Толковый словарь русского языка. URL: http://slovarozhegova.ru/ word.php?wordid=115 (дата обращения: 24.12.2018).

11. Полещук Ж.А., Галетта И.В. Использование информационных технологий в системе управления персоналом // Проблемы современной науки и образования. 2017. № 23. C. 28-31.

12. Лопашенко Н.А. Посягательства на собственность. М. : Норма, Инфра-М, 2012. $528 \mathrm{c}$. 
Nekrasov Vasily N., Vologda Institute of Law and Economics of the Federal Penitentiary Service of Russia (Vologda, Russian Federation)

TECHNOLOGIES IN THE CRIMINAL LEGISLATION OF RUSSIA: PROBLEMS AND PROSPECTS

Keywords: criminal law, innovative activity, crime.

\section{DOI: $10.17223 / 22253513 / 37 / 7$}

In this paper, the author tried to consider the impact of such innovation results as technology on domestic criminal law and to understand whether the legislator is ready for them.

In the current Criminal Code of the Russian Federation, the legislator does not once use a single general concept in relation to technical innovations, which allows to characterize its various elements. At the same time, the legislator traditionally uses such private terms as tools, means, equipment, system, etc.

When considering this issue, the first thought that comes to mind is that technical innovations in the Criminal Code are regarded as instruments or means of committing a crime.

In criminal law theory, there are many points of view on the question of distinguishing between "instrument" and "means" of crime. The Criminal Code of the Russian Federation does not clearly understand the concepts under analysis. Technical innovations, such as equipment by domestic lawmakers, are regarded as instruments and means of committing a crime.

The above concepts were traditionally used by the legislator to construct the norms of the Russian criminal law. At the same time, due to the active development of innovation activity, new technical innovations are appearing today, which, firstly, did not exist before, and secondly, they have a number of specific features.

At the same time, definitions that were not previously used in the Russian criminal law, which allow judging about new possibilities of technology, which only stimulate the discussion about the legal status of technology, both in criminal law and in legislation as a whole, are already in place today.

Social relations are undergoing certain changes as a result of innovative activities. In this regard, the object of crime is also being transformed. As a result, a new type of property is emerging, namely intellectual property, which is also subject to criminal law protection.

It seems that today there is a need to combine the norms in the field of crimes that infringe on innovative activity into a separate group of norms. These social relations have a number of features that make it possible to consider forming them into a separate type of crime object.

Separating groups of crimes in the area of innovative activity will be of great importance. In particular, it will make it possible to establish public danger in relation to a group of crimes and to analyse changes in the degree of public danger of crime depending on the type of qualifying and attracting circumstances.

\section{References}

1. Mukhamedzyanova, D. (2017) Roboty dolzhny nesti ugolovnuyu otvetstvennost' [Robots should bear criminal responsibility]. [Online] Available from: https://hightech.fm/ 2017/04/04/intelligence-systems (Accessed: 5th November 2018).

2. Polomoshnov, A.F., Lavrukhina, I.M. \& Polomoshnov, P.A. (2015) Filosofiya $i$ sovremennyy mir [Philosophy and the Modern World]. Persianovsky: Donskoy GAU.

3. The Russian Federation. (2011) O natsional'noy platezhnoy sisteme: federal'nyy zakon ot 27.06.2011 № 161-FZ [On the national payment system: Federal Law No. 161-FZ of june 27, 2011]. [Online] Available from: http://www.consultant.ru/document/cons_doc_LAW_115625/

4. Denisova, A.S. (2005) Ugolovno-pravovoe znachenie orudiy i sredstv soversheniya prestupleniya [Criminal and legal value of instruments and means of committing a crime]. Law Cand. Diss. Moscow. 
5. Zhukova, E.A. (2007) Hi-Tech: dinamika vzaimodeystviy nauki, obshchestva $i$ tekhnologiy [Hi-Tech: dynamics of interactions between science, society and technology]. Abstract of Philosophy Dr. Diss. Tomsk.

6. Vlasova, E.M. (2015) Izmenenie otnosheniya chelovek - tekhnika v sovremennom obshchestve: problema novogo gumanizma [Changing the relationship between man and technology in modern society: the problem of new humanism]. Mezhdunarodnyy zhurnal prikladnykh i fundamental'nykh issledovaniy. 1. pp. 170-173.

7. Dydrov, A.A., Pochinskaya, V.A. \& Sharipova, A.R. (2018) Mechanization of a man and humanization of a machine: tendencies of the existence of man and technology. Sotsium $i$ vlast' - Society and Power. 3(71). pp. 7-14. (In Russian).

8. Barbakova, K.G., Voytenko, L.I., Gudkov, L.D. et al. (1989) FRG glazami zapadnogermanskikh sotsiologov: tekhnika - intellektualy - kul'tura [FRG through the eyes of West German sociologists: technology - intellectuals - culture]. Moscow: Nauka.

9. Wikipedia.org. (n.d.) Avtomatizirovannaya sistema upravleniya [Automated control system]. [Online] Available from: https://ru.wikipedia.org/wiki/Avtomatizirovannaya_sistema_ upravleniya (Accessed: 22nd December 2018).

10. Ozhegov, S.I. (n.d.) Tolkovyy slovar' russkogo yazyka [Explanatory Dictionary of the Russian Language]. [Online] Available from: http://slovarozhegova.ru/word.php?wordid=115 (Accessed: 24th December 2018).

11. Poleshchuk, Zh.A. \& Geleta, I.V. (2017) Usage of information technologies in human resources management system. Problemy sovremennoy nauki i obrazovaniya - Problems of Modern Science and Education. 23. pp. 28-31. (In Russian).

12. Lopashenko, N.A. (2012) Posyagatel'stva na sobstvennost' [Property infringement]. Moscow: Norma, Infra-M. 